Board of Governors of the Federal Reserve System

International Finance Discussion Papers

Number 703

May 2001

PERMANENT AND TRANSITORY COMPONENTS OF BUSINESS CYCLES: THEIR RELATIVE IMPORTANCE AND DYNAMIC RELATIONSHIP

\author{
Chang-Jin Kim, Jeremy Piger and Richard Startz
}

NOTE: International Finance Discussion Papers are preliminary materials circulated to stimulate discussion and critical comment. References in publications to International Finance Discussion Papers (other than an acknowledgment that the writer has had access to unpublished material) should be cleared with the author or authors. Recent IFDPs are available on the Web at www.bog.frb.fed.us. 


\title{
PERMANENT AND TRANSITORY COMPONENTS OF BUSINESS CYCLES: THEIR RELATIVE IMPORTANCE AND DYNAMIC RELATIONSHIP
}

\author{
Chang-Jin Kim, Jeremy Piger and Richard Startz ${ }^{*}$
}

\begin{abstract}
This paper investigates the relationship between permanent and transitory components of U.S. recessions in an empirical model allowing for business cycle asymmetry. Using a common stochastic trend representation for real GNP and consumption, we divide real GNP into permanent and transitory components, the dynamics of which are different in booms vs. recessions. We find evidence of substantial asymmetries in postwar recessions, and that both the permanent and transitory component have contributed to these recessions. We also allow for the timing of switches from boom to recession for the permanent component to be correlated with switches from boom to recession in the transitory component. The parameter estimates suggest a specific pattern of recessions: switches in the permanent component lead switches in the transitory component both when entering and leaving recessions.
\end{abstract}

Keywords: asymmetry, economic fluctuations, Markov-switching.

*Kim is a professor of economics at Korea University, Piger is an economist in the International Finance Division of the Federal Reserve Board and Startz is a professor of economics at the University of Washington. Kim acknowledges support from the National Science Foundation under grant SES9818789 and from the Department of Economics at the University of Washington. Piger acknowledges support from the Grover and Creta Ensley Fellowship in Economic Policy. Startz acknowledges support from the National Science Foundation under grant SES9711301. We received helpful comments from James Morley, Charles Nelson, and seminar participants at the University of Virginia, University of Washington and Washington University. This paper is based on chapter 3 of Piger's Ph.D. dissertation at the University of Washington. The views in this paper are solely the responsibility of the authors and should not be interpreted as reflecting the views of the Board of Governors of the Federal Reserve System or of any other person associated with the Federal Reserve System. 
The study of business cycle asymmetry, in which the dynamics of recessions are modeled differently from expansions, has a long history in the economics literature. For example, much early work documenting business cycle facts, of which the research of Burns and Mitchell (1946) at the NBER is a well-known example, focused on recessions separately from expansions. One observation made by these researchers was that the negative shocks that lead to recessions tend to be larger than the other shocks observed over the business cycle. This regularity was also the focus of Neftci's (1984) investigation of asymmetry in unemployment rate dynamics, work that sparked the modern asymmetry literature. Hamilton (1989) demonstrated that large negative shocks can be captured by modeling recessions with discrete shocks, and that the occurrence of these shocks can be modeled as a Markov process. The persistence of business cycle fluctuations has also been the subject of much research, following Nelson and Plosser's (1982) challenge to the traditional view that recessions are transitory dips below trend.

In this paper we investigate the business cycle allowing for asymmetry between booms and recessions, modeled with discrete as well as continuous shocks to the macro economy, and allowing for this asymmetry to arise from either the permanent or transitory component of output. We find very substantial asymmetries, suggesting that both discrete and continuous shocks are important in understanding the business cycle. We find that both the transitory and permanent component of output contribute to short-run fluctuations. Finally, we uncover a surprising, and very strong, temporal pattern to recessions: the permanent component leads the transitory component both when entering and leaving recessions.

The details of our empirical model are as follows. We specify real GNP and consumption as a cointegrated system with a common, random walk, stochastic trend. This yields a natural division of real GNP into permanent and transitory components. The permanent component is 
the common stochastic trend shared by real GNP and consumption while the transitory component is the deviation of real GNP from this common trend. We then allow the dynamics of both the permanent and transitory component to differ in expansions vs. recessions. Specifically, during each quarter a recession is in effect, we allow the growth rate of the common stochastic trend and the level of the transitory component to be reduced by discrete shocks in addition to the effects of continuous shocks that are present at all times. These discrete shocks, present only during recessions, allow the model to capture recessions that are characterized by relatively large, negative shocks. We endogenously estimate when the switches of the permanent and transitory components between the expansion state and the recession state occur by modeling the switching with two Markov-switching state variables.

In addition, we investigate what dependence might exist, both contemporaneously and at lags, between the timing of switches in the permanent component from boom to recession and corresponding switches in the transitory component. We accomplish this by modeling the evolution of the two Markov-switching state variables as driven by a single, 4-state Markovswitching process. We then ask questions of the following form: Does the probability of say, a switch to the recession state in the transitory component depend on current and lagged recessionary switches in the permanent component? These sorts of questions can be answered using various hypothesis tests regarding the transition probabilities of the Markov-switching process.

The results suggest that recessions can be usefully characterized by a typical pattern: Recessions begin with a switch to the recession state in the permanent component, characterized by discrete reductions to the growth rate of the common stochastic trend. The result that recessions begin with a switch in the permanent component, rather than a switch in the transitory 
component, may suggest sources underlying the recessions, although we do not pursue this avenue in this paper. During most recessions, following the reduction in trend growth rate, a corresponding switch to the recession state in the transitory component occurs, characterized by discrete reductions to its level. These discrete reductions to the level of the transitory component contribute a bit more to movements in real GNP during recessions than the discrete reductions to the growth rate of the common stochastic trend. The permanent component then switches back to its expansionary state, in most cases at least one quarter before the transitory component switches to its expansionary state. The recession then ends and the economy gradually asymptotes to its new growth path.

Figure 1, illustrating a typical business cycle, presents a simulation of our estimated preferred model (discussed in section 3.3). We track three variables: log output, $y_{t}$, the permanent component, $x_{t}$, and the transitory component, $z_{t} \cdot{ }^{1}$ During expansions, output has a trend growth rate of just under 1 percent per quarter. A recession begins with a drop to a lower growth rate, about 0.4 percent per quarter, simulated here beginning in quarter 9 . This lower growth trend continues (probabilistically) for four quarters, so the cumulative permanent loss in the level of output is about 2.4 percent. Following the beginning of the reduction in trend growth rate, a shorter sequence of discrete reductions to the level of the transitory component, beginning probabilistically in quarters 12 and 13, occurs. These discrete reductions, which reduce the level of the transitory component by about 1.5 percent each quarter, contribute a bit more to the movements in output than the discrete reductions to the growth rate of the permanent component. We estimate that the total short run effect of the discrete reductions to the transitory component

\footnotetext{
${ }^{1}$ For readability Figure 1 omits some elements of our full estimated model. First, the rate of trend growth during expansions dropped after 1973 from about 1 percent per quarter to about three-quarters of a percent. Second, we also estimate continuous permanent and transitory shocks which would cause significant fluctuations around the lines shown for $x_{t}$ and $z_{t}$.
} 
is about 1.25 times as large as that of the reductions in trend growth rate. Finally, in the recovery phase the effect of the reductions to the transitory component gradually wears off.

In the following section we discuss the business cycle asymmetry literature that we build on in this paper. Section 2 formally presents the empirical model and discusses the various restrictions to be tested. In section 3 we present and interpret the estimation results and hypothesis tests. Section 4 concludes.

\section{Business Cycle Asymmetry - Evidence and Modeling Techniques}

We consider two forms of business cycle asymmetry in this paper, both of which can capture recessions that are characterized by relatively large, negative shocks. In the first, the dynamics of the permanent component of output differ from boom to recession. Because asymmetry is modeled in the permanent component, the asymmetric portion of recessions by definition have permanent effects. In other words, the level of output is permanently lower than if the recession had never occurred. In the second, asymmetry is modeled with different dynamics in the transitory component of output. Here, the asymmetric portion of recessions has only transitory effects. Following a recession, output rebounds, or "peak-reverts", to the level that would have obtained had no recession occurred.

These two forms of business cycle asymmetry have received a substantial amount of attention in the empirical and theoretical literature. In the empirical literature, perhaps more attention has been paid to capturing asymmetry in the permanent component. Much of this work has focused on modeling asymmetry using Hamilton's (1989) two state Markov-switching model, in which asymmetry is captured by allowing the average growth rate of the trend component to differ from expansion to recession. Many authors have attempted to test for 
asymmetry by comparing Hamilton's model to linear alternatives. Both Hansen (1992) and Garcia (1998), using classical likelihood based test procedures, find that linear autoregressive models cannot be rejected in favor of Hamilton's (1989) model for real GNP. However, using Bayesian techniques, Chib (1995) and Koop and Potter (1999) find evidence that the Markovswitching model outperforms linear models. Also, Diebold and Rudebusch (1996) and Kim and Nelson (1999a) argue that univariate techniques have low power in detecting a specific form of business cycle asymmetry as the data may be obscured by idiosyncratic variation. They find that evidence in favor of Hamilton's model is much stronger when viewed in a multivariate context.

In theoretical models, this type of business cycle asymmetry is often modeled as endogenous switching between "good" and "bad" trend growth states. Howitt and McAfee (1992) employ a model of switching consumer confidence which leads to multiple equilibria with statistical properties well characterized by Markov-switching. In Cooper (1994), agents choose between multiple equilibria and then remain in the chosen equilibrium until a large shock induces a switch. Acemoglu and Scott (1997) and Startz (1998) also employ models in which shocks generate endogenous switching between growth states.

Asymmetry in the transitory component of output has also been investigated extensively in the literature. This type of asymmetry is most often associated with Friedman's $(1964,1993)$ “plucking” model of recessions. In Friedman's model, recessions are caused by large negative shocks and are followed by periods of rapid recovery. Here, business cycles have three phases: recession, high-growth recovery phase, and normal expansion phase. Wynne and Balke $(1992,1996)$ find that the deeper the recession the stronger the ensuing recovery while Sichel (1994) finds evidence of a high growth recovery phase following recessions. Both of these results are implications of Friedman's model. Another implication of "plucking” recessions is 
that negative shocks are less persistent than positive shocks. ${ }^{2}$ Beaudry and Koop (1993) showed that a variable measuring the depth of real GNP below its historic high was useful for predicting changes in output. They use this variable to investigate impulse response functions for negative vs. positive shocks, and show that negative shocks are much less persistent.

The pattern of recessions characterized by asymmetry in the transitory component is consistent with a wide variety of theoretical business cycle models. In demand driven models, output might be driven into recession by a large infrequent demand shock. Following the recession, output grows faster than when at trend because resources are underutilized. Walrasian models can also generate peak-reversion if recessions are partially absorbed by running down the capital stock. Then, just as in Solow type growth models, the economy will experience faster growth until the capital stock is restored to its new steady state value.

How are these two types of asymmetry typically captured in time series models of the business cycle? One technique that by now has a long tradition is the use of Markov-switching models. Hamilton (1989) captured business cycle asymmetry in the permanent component of real GNP with a sequence of discrete Markov-switching reductions to the average growth rate of trend in an ARIMA process. Here, the relatively large shocks that cause recessions are shocks to the average growth rate of trend. One consequence of this modeling choice is that the asymmetric portion of recessions have permanent effects on the level of output. Diebold and Rudebusch (1996), Kim and Yoo (1995), Chauvet (1998) and Kim and Nelson (1998) extend the Hamilton model to a multivariate framework meant to capture both asymmetry and comovement across different sectors of the economy. Asymmetry in the transitory component can

\footnotetext{
${ }^{2}$ If recessions are caused by large transitory shocks that are not present during expansions, there will be less evidence of persistence during recessions than during expansions. Therefore, negative shocks will on average have less persistence than positive shocks.
} 
also be modeled using Markov-switching models. In a time series model meant to capture the spirit of Friedman's (1964, 1993) plucking model, Kim and Nelson (1999b) model business cycle asymmetry in real GNP with discrete, negative Markov-switching reductions to the level of the transitory component of an ARIMA process. Because these discrete shocks operate only through the transitory component, they have only temporary effects on the level of output. In other words, output "peak reverts" to trend following a recession.

Our model extends this literature in two main ways. First, we combine asymmetry in both the permanent and transitory component into a single multivariate model of the business cycle and identify correlation between the switches in these two components over the business cycle. Kim and Murray (1999) and Kim and Piger(1999) also estimate models incorporating both types of asymmetry, the former to indicator variables describing a new coincident index and the latter to a simple neoclassical growth model of real GNP, consumption and investment. However, both of these papers use strong correlation assumptions to describe the relationship between switches in the permanent and transitory component. In the former the shifts are assumed independent while in the latter the shifts come from the same state, and are therefore perfectly correlated. In this paper we identify the contemporaneous and lead-lag correlation between switches in the dynamics of the permanent and transitory components. This yields some interesting insights into the pattern of permanent and transitory movements in output over the business cycle. Our second extension is to analyze asymmetry within a cointegrated system of real GNP and consumption. Recent contributions by Cochrane (1994) and Fama (1992) suggest that consumption can play a useful role in identifying the trend in real GNP, and that this trend component can differ substantially from that implied by univariate decompositions. In this paper we employ this methodology to identify asymmetric features of the permanent and transitory component. 


\section{Model Specification}

\subsection{A Model of Business Cycle Asymmetry}

Consider the following unobserved components model of business cycle fluctuations:

$$
\begin{aligned}
& y_{t}=\alpha+x_{t}+z_{t}^{y} \\
& c_{t}=x_{t}+z_{t}^{c}
\end{aligned}
$$

Here, the log of U.S. real GNP $\left(y_{t}\right)$ and the log of U.S. consumption of non-durables and services $\left(c_{t}\right)$ are divided into a common stochastic trend $x_{t}$ and transitory components $z_{t}^{y}$ and $z_{t}^{c}$. This specification is based on simple neoclassical growth models such as King, Plosser and Rebelo (1988) suggesting that output and consumption exhibit balanced stochastic growth, that is they are cointegrated with cointegrating vector $(1,-\gamma)$ where $\gamma$ is equal to one. Here we will estimate $\gamma$ rather than impose the theoretical value of one.

We model asymmetry in the trend component as in Hamilton (1989):

$x_{t}=\mu_{1}^{*} S_{t}^{P}+\mu_{0}^{*}\left(1-S_{t}^{P}\right)+x_{t-1}+v_{t}(2)$

where $v_{t} \sim N\left(0, \sigma_{v}^{2^{*}}\right)$, and $S_{t}^{P}=\{0,1\}$ indicates the state of the economy for the trend

component. Labeling $S_{t}^{P}=1$ as the recession state, the average growth rate of $x_{t}$ is given by $\mu_{0}^{*}$ during expansions and $\mu_{1}^{*}$ during recessions. Thus, the average growth rate of the trend is reduced by the discrete amount $\mu_{0}^{*}-\mu_{1}^{*}$ during each quarter that $S_{t}^{P}=1$.

To incorporate asymmetry in the transitory component of real GNP we allow $z_{t}^{y}$ to undergo regime switching as in Kim and Nelson (1999b). Formally:

$\phi(L) z_{t}^{y}=\tau S_{t}^{T}+\varepsilon_{t}$ 
where $\phi(L)$ has all roots outside the unit circle, $\varepsilon_{t} \sim N\left(0, \sigma_{\varepsilon}^{2^{*}}\right)$ and is uncorrelated with $v_{t}$, and $S_{t}^{T}=\{0,1\}$ indicates the state of the economy for the transitory component. Labeling $S_{t}^{T}=1$ as the recessionary state, $z_{t}^{y}$ is reduced by the discrete amount, $\tau$, during each quarter that $S_{t}^{T}=1$. However, when the economy returns to normal times, that is $S_{t}^{T}=0$, the effects of past $\tau S_{t}^{T}$ wear off in accordance with the transitory autoregressive dynamics and the economy reverts back to the stochastic trend. The farther the economy is plucked down, the faster the growth of the economy as it "bounces back" or "peak-reverts" to trend.

In the model above, real GNP and consumption share a common stochastic trend, modeled as a random walk with a switching drift term. Both Cochrane (1994) and Fama (1992) show that the level of consumption of non-durables and services is very close to a random walk, a result consistent with the permanent income hypothesis. As Cochrane and Fama note, this result, combined with the cointegration of output and consumption, suggests that consumption can usefully be employed as the trend in real GNP. Building on this work, we use consumption to anchor the trend in real GNP by specifying that consumption differs from $\not x_{t}$ by only white noise $z_{t}^{c}$, which is uncorrelated with $z_{t}^{y}$ and $v_{t}$. As suggested by Sargent (1989) $z_{t}^{c}$ might be thought of as measurement error. Specifically: $z_{t}^{c} \sim$ i.i.d. $\left(0, \sigma_{z^{c}}^{2}\right)$

When estimating models such as the one given in equations (1)-(4), structural change in the macroeconomy, to the extent that it affects key parameters of the model, should be taken into account. In this sense, the last 30 years of U.S. macroeconomic data are problematic, as it contains two well documented sources of structural change relevant to this model. First, there is a large literature suggesting that the growth rate of productivity slowed at some point in the 
postwar sample, with the predominant view that this slowdown roughly coincides with the first OPEC oil shock. For example, Perron (1989) identifies 1973 as the date of a break in the trend growth of U.S. quarterly real GNP. Using multivariate techniques, Bai, Lumsdaine and Stock (1998) find evidence of a reduction in the growth rate of the common stochastic trend shared by real GNP and consumption, dating the break to the late 1960's. To account for this productivity slowdown we allow for a reduction in the average growth rate of trend beginning in $1973 .{ }^{3}$ This is accomplished by defining:

$\mu_{0}^{*}=\mu_{0}+\mu^{k} D U 1_{t}$

$\mu_{1}^{*}=\mu_{1}+\mu^{k} D U 1_{t}$

where $D U 1_{t}$ is 0 before the first quarter of 1973 and 1 afterwards. The second structural change we consider is in the variability of U.S. real GNP, which has seen a marked reduction in the last 15 years. Kim and Nelson (1999c) and McConnell and Perez-Quiros (2000) both date this break to 1984 . To account for this variability reduction we define:

$$
\begin{aligned}
& \sigma_{\varepsilon}^{*}=\sigma_{\varepsilon}\left(1-D U 2_{t}\right)+\sigma_{\varepsilon}^{k} D U 2_{t} \\
& \sigma_{v}^{*}=\sigma_{v}\left(1-D U 2_{t}\right)+\sigma_{v}^{k} D U 2_{t}
\end{aligned}
$$

where $D U 2_{t}$ is 0 before the first quarter of 1984 and 1 afterwards. ${ }^{4}$

\subsection{Modeling the Correlation Between Switches in the Permanent and Transitory Components}

In this section we discuss the method by which we allow the timing of switches in the permanent and transitory components from boom to recession to be correlated. We do this

\footnotetext{
${ }^{3}$ Preliminary estimation suggested that if a productivity slowdown is not incorporated the autoregressive dynamics of $z_{t}^{y}$ are very persistent. This is consistent with Perron's (1989) finding that unit root tests are biased towards nonrejection if a break in mean growth has occurred and is not allowed. Our results are robust to dating the structural break to the late 1960's, as suggested by Bai, Lumsdaine and Stock (1998).

${ }^{4}$ We also estimated the model on the subsample through 1984, thus omitting the need for the dummy variable $D U 2_{t}$. Parameter estimates for this estimation were quantitatively similar to the estimates for the full sample including $D U 2_{t}$.
} 
through assumptions regarding the processes driving $S_{t}^{P}$ and $S_{t}^{T}$. Note that each of $S_{t}^{P}$ and $S_{t}^{T}$ can take on one of two values, 0 or 1 , corresponding to expansion or recession. Therefore, $S_{t}^{P}$ and $S_{t}^{T}$ as a pair can take on one of four different combinations. For the analysis that follows it will be useful to think in terms of this four combination, or four state model:

\begin{tabular}{lll} 
Value of $S_{t}^{P}$ & Value of $S_{t}^{T}$ & Interpretation \\
\hline 0 & 0 & Expansion \\
0 & 1 & Recession State for Transitory Component Only \\
1 & 0 & Recession State for Permanent Component Only \\
1 & 1 & Recession State for Both Components
\end{tabular}

We assume that the four states above evolve according to a first order Markov process with the following sixteen transition probabilities: $P\left(S_{t}^{P}=i, S_{t}^{T}=j \mid S_{t-1}^{P}=k, S_{t-1}^{T}=q\right)$, $i, j, k, q=0,1$. For particular realizations of $S_{t}^{P}$ and $S_{t}^{T}$ these can be represented with the notation, $p_{\left.S_{t}^{P} S_{t}^{T}\right|_{t-1} ^{p} S_{t-1}^{T}}$. For example, $p_{10 \mid 01}$ would correspond to $P\left(S_{t}^{P}=1, S_{t}^{T}=0 \mid S_{t-1}^{P}=0, S_{t-1}^{T}=1\right)$. These transition probabilities are summarized in the following table in which the $m, n^{\prime}$ th element is the probability of moving to the value of $S_{t}^{P}$ and $S_{t}^{T}$ specified in row $m$ given that the values of $S_{t-1}^{P}$ and $S_{t-1}^{T}$ were as in column $n$ :

\begin{tabular}{|c|c|c|c|c|}
\hline & $\left(S_{t-1}^{P}=0, S_{t-1}^{T}=0\right)$ & $\left(S_{t-1}^{P}=0, S_{t-1}^{T}=1\right)$ & $\left(S_{t-1}^{P}=1, S_{t-1}^{T}=0\right)$ & $\left(S_{t-1}^{P}=1, S_{t-1}^{T}=1\right)$ \\
\hline$\left(S_{t}^{P}=0, S_{t}^{T}=0\right)$ & $p_{00 \mid 00}$ & $p_{00 \mid 01}$ & $p_{00 \mid 10}$ & $p_{00 \mid 11}$ \\
\hline$\left(S_{t}^{P}=0, S_{t}^{T}=1\right)$ & $p_{01100}$ & $p_{01 \mid 01}$ & $p_{01 \mid 10}$ & $p_{0|| 11}$ \\
\hline$\left(S_{t}^{P}=1, S_{t}^{T}=0\right)$ & $p_{10 \mid 00}$ & $p_{10 \mid 01}$ & $p_{10 \mid 10}$ & $p_{10 \mid 11}$ \\
\hline$\left(S_{t}^{P}=1, S_{t}^{T}=1\right)$ & $\begin{array}{l}p_{11 \mid 00}=1-p_{00 \mid 00}- \\
p_{01 \mid 00}-p_{10 \mid 00}\end{array}$ & $\begin{array}{l}p_{11 \mid 01}=1-p_{00 \mid 01}- \\
p_{01 \mid 01}-p_{10 \mid 01}\end{array}$ & $\begin{array}{l}p_{1|| 10}=1-p_{00 \mid 10^{-}} \\
p_{01|| 10}-p_{10 \mid 10}\end{array}$ & $\begin{array}{l}p_{1|| 11}=1-p_{00 \mid 11}- \\
p_{0|| 11}-p_{10 \mid 11}\end{array}$ \\
\hline
\end{tabular}


In this general specification there are 16 total transition probabilities, 12 that must be estimated and four that can be recovered via the restriction that the probabilities in each column must sum to one. We will call this model of the correlation between $S_{t}^{P}$ and $S_{t}^{T}$ Model $1 .^{5}$

The transition probabilities in Model 1 allow for two kinds of interdependence between $S_{t}^{P}$ and $S_{t}^{T}$. The first is that the evolution of $S_{t}^{P}$ and $S_{t}^{T}$ depend on both $S_{t-1}^{P}$ and $S_{t-1}^{T}$, thus lagged values of both states influence where a state is today. Secondly, Model 1 allows $S_{t}^{P}$ and $S_{t}^{T}$ to be contemporaneously correlated conditional on lagged values of the states, that is $P\left(S_{t}^{P}=i, S_{t}^{T}=j \mid S_{t-1}^{P}=k, S_{t-1}^{T}=q\right) \neq P\left(S_{t}^{P}=i \mid S_{t-1}^{P}=k, S_{t-1}^{T}=q\right) * P\left(S_{t}^{T}=j \mid S_{t-1}^{P}=k, S_{t-1}^{T}=q\right)$. As will be discussed further in the next section, we will also be interested in a model in which $S_{t}^{P}$ and $S_{t}^{T}$ are contemporaneously uncorrelated conditional on lagged values of the states. This restriction can be imposed by specifying the 12 estimated transition probabilities of Model 1 as a function of 8 underlying parameters. This model, which we call Model 2, can be summarized as follows:

\section{Model 2 (Transition Probabilities to Estimate = 8):}

The evolution of both $S_{t}^{P}$ and $S_{t}^{T}$ depend on both $S_{t-1}^{P}$ and $S_{t-1}^{T}$. However, conditional on $S_{t-1}^{P}$ and $S_{t-1}^{T}, S_{t}^{P}$ and $S_{t}^{T}$ are uncorrelated, that is

$$
\begin{aligned}
& P\left(S_{t}^{P}=i, S_{t}^{T}=j \mid S_{t-1}^{P}=k, S_{t-1}^{T}=q\right)= \\
& P\left(S_{t}^{P}=i \mid S_{t-1}^{P}=k, S_{t-1}^{T}=q\right) * P\left(S_{t}^{T}=j \mid S_{t-1}^{P}=k, S_{t-1}^{T}=q\right) .
\end{aligned}
$$

We will also be interested in a model in which $S_{t}^{P}$ and $S_{t}^{T}$ are independent for comparison purposes. This model can be represented as a restricted version of Model 1 and is summarized below:

\footnotetext{
${ }^{5}$ A detailed description of the specification of transition probabilities for all models considered in this section is
} 


\section{Model 3 (Transition Probabilities to Estimate $=4$ )}

$S_{t}^{P}$ and $S_{t}^{T}$ are independent: The evolution of $S_{t}^{P}$ can be completely described based on $S_{t-1}^{P}$ and that of $S_{t}^{T}$ can be completely described in terms of $S_{t-1}^{T}$.

\section{Hypothesis Tests and Estimation Results}

\subsection{A Look at the Data}

The data are quarterly observations on 100 times the logarithm of U.S. real GNP and U.S real consumption of non-durables and services. Table 1 contains summary statistics for this data. All data was obtained from the DRI Basics Economic database and span from the first quarter of 1952 to the second quarter of 1998.

The model in Section 2 imposes a common stochastic trend in the logarithms of output and consumption. Thus, we are interested in the empirical evidence regarding the integration and cointegration properties of the data. First of all, using standard univariate unit root tests developed by Dickey and Fuller (1979), we fail to reject the null hypotheses that the logarithm of real GNP and consumption are integrated at the $10 \%$ level. Details of these tests are given in Table 1. To investigate the cointegration properties of the data we have a choice of tests that can be employed. As is pointed out in Bai, Lumsdaine and Stock (1998), conventional multivariate and system-based tests suffer from low power and large size distortions. However, in models where a suitable cointegrating vector can be posited in advance, Stock (1994) shows that univariate Dickey-Fuller (1979) t-tests with BIC lag selection have good size properties. The neoclassical growth theory that motivates the cointegration of GNP and consumption gives us a theoretical cointegrating vector of $(1,-1)$. We therefore form the difference between the log of real GNP and the log of consumption and perform the univariate Dickey-Fuller tests. We reject

provided in the appendix. 
the null hypothesis of a unit root in this difference at the $5 \%$ level. Details of this test are given Table 1. This is consistent with the results of other investigations of the cointegration properties of output and consumption, such as King, Plosser, Stock and Watson (1991), Bai, Lumsdaine, and Stock (1998) and Stock and Watson (1999). ${ }^{6}$

\subsection{Choice of Preferred Model - Hypothesis Tests}

In Section 2, we distinguished between three different models, Model 1, our most general model of interdependence between $S_{t}^{T}$ and $S_{t}^{P}$, and Models 2 and 3 which placed restrictions on this interdependence. In the following, we present estimation results and likelihood ratio tests meant to distinguish a preferred model from these three models. The estimated parameters and likelihood values for all models were calculated via Kim's (1993a, 1993b, 1994) approximate maximum likelihood algorithm ${ }^{7}$.

The parameter estimates for Model 1, our most general model, are presented in Table 2 while the 4-state transition probability matrix implied by these estimates is presented in Table 3. Using Table 3 one can see that the estimated transition probabilities in Model 1 are consistent with the restriction imposed in Model 2 that $S_{t}^{P}$ and $S_{t}^{T}$ are conditionally uncorrelated. Indeed these restrictions hold with near equality. For example, consider the probability of only the permanent component switching to its recession state following an expansion, $P\left(S_{t}^{P}=1, S_{t}^{T}=0 \mid S_{t-1}^{P}=0, S_{t-1}^{T}=0\right)=0.04$. The probability of the permanent component switching

to its recession state following an expansion, $P\left(S_{t}^{P}=1 \mid S_{t-1}^{P}=0, S_{t-1}^{T}=0\right)=$ $P\left(S_{t}^{P}=1, S_{t}^{T}=0 \mid S_{t-1}^{P}=0, S_{t-1}^{T}=0\right)+P\left(S_{t}^{P}=1, S_{t}^{T}=1 \mid S_{t-1}^{P}=0, S_{t-1}^{T}=0\right)$ is also equal to 0.04 .

\footnotetext{
${ }^{6}$ Evans and Lewis (1993) show that cointegration tests can be biased in favor of the null hypothesis if a series in the cointegrating equation undergoes Markov regime switching. Since we reject the null hypothesis this does not seem to be a significant problem in this case.
} 
Finally, the probability of the transitory component not switching to its recession state following an expansion, $P\left(S_{t}^{T}=0 \mid S_{t-1}^{P}=0, S_{t-1}^{T}=0\right)=P\left(S_{t}^{P}=0, S_{t}^{T}=0 \mid S_{t-1}^{P}=0, S_{t-1}^{T}=0\right)+$ $P\left(S_{t}^{P}=1, S_{t}^{T}=0 \mid S_{t-1}^{P}=0, S_{t-1}^{T}=0\right)$ is equal to 1.0 . Thus, these probabilities satisfy: $P\left(S_{t}^{P}=1, S_{t}^{T}=0 \mid S_{t-1}^{P}=0, S_{t-1}^{T}=0\right)=P\left(S_{t}^{P}=1 \mid S_{t-1}^{P}=0, S_{t-1}^{T}=0\right) * P\left(S_{t}^{T}=0 \mid S_{t-1}^{P}=0, S_{t-1}^{T}=0\right)$

Such preliminary tests suggest Model 2 might provide a good approximation of the interdependence described in Model 1. Tables 4 and 5 present the estimated parameters and the full 16 element transition probability matrix built up from the eight estimated transition probabilities of Model 2. Note that the estimated parameters and implied 4-state transition probability matrix from Models 1 and 2 are identical to two decimal places, and the likelihood values are very close. A likelihood ratio test confirms that Models 1 and 2 are essentially indistinguishable, the p-value is .99. Therefore, it appears that the correlation structure assumptions made in Model 2 are not rejected in favor of Model 1. In other words, conditional on lagged values of each state variable, $S_{t}^{P}$ and $S_{t}^{T}$ are conditionally uncorrelated.

Before discussing the implications of the estimated transition probabilities it is of interest to see if our preferred model allowing for dependence, Model 2, provides any improvement over the model forcing $S_{t}^{P}$ and $S_{t}^{T}$ to be independent, Model 3. Estimation of Model 3 yields a likelihood value of 21.43, giving a likelihood ratio test statistic for the test of Model 3 vs. Model 2 of 9.86. With four degrees of freedom (four transition probabilities vs. eight), the p-value for this test is .04 , leading us to reject the null hypothesis of independence at the $5 \%$ level.

Thus, it appears that Model 2, which allows for the evolution of $S_{t}^{P}$ and $S_{t}^{T}$ to depend on lagged values of both state variables, is preferred over the model in which $S_{t}^{P}$ and $S_{t}^{T}$ are

\footnotetext{
${ }^{7}$ After various diagnostic checks, we settled on a lag order of 2 for $\phi(L)$.
} 
independent. Given this result, it is interesting to investigate whether one or the other of these states is playing a larger role in rejecting the null hypothesis. In particular, is $S_{t}^{T}$ more dependent on $S_{t-1}^{P}$ than $S_{t}^{P}$ is on $S_{t-1}^{T}$ ? Does $S_{t}^{P}$ Granger cause $S_{t}^{T}$ or vice versa? Such questions can be answered by estimating the following two models:

Model 2* ( $S_{t}^{P}$ Granger Causes $S_{t}^{T}$, Transition Probabilities to Estimate =6) $S_{t}^{P}$ and $S_{t}^{T}$ are dependent in the following way: The evolution of $S_{t}^{P}$ can be completely described based on $S_{t-1}^{P}$ only, that is $P\left(S_{t}^{P}=i \mid S_{t-1}^{P}=k, S_{t-1}^{T}=q\right)=P\left(S_{t}^{P}=i \mid S_{t-1}^{P}=k\right)$. The evolution of $S_{t}^{T}$ can be completely described in terms of both $S_{t-1}^{P}$ and $S_{t-1}^{T}$, that is $P\left(S_{t}^{T}=j \mid S_{t-1}^{P}=k, S_{t-1}^{T}=q\right) \neq P\left(S_{t}^{T}=j \mid S_{t-1}^{T}=q\right)$.

\section{Model 2*** ( $S_{t}^{T}$ Granger Causes $S_{t}^{P}$, Transition Probabilities to Estimate $=6$ )}

$S_{t}^{P}$ and $S_{t}^{T}$ are dependent in the following way: The evolution of $S_{t}^{P}$ can be completely described in terms of both $S_{t-1}^{P}$ and $S_{t-1}^{T}$, that is $P\left(S_{t}^{P}=i \mid S_{t-1}^{P}=k, S_{t-1}^{T}=q\right)$ $\neq P\left(S_{t}^{P}=i \mid S_{t-1}^{P}=k\right)$. The evolution of $S_{t}^{T}$ can be completely described based on $S_{t-1}^{T}$ only, that is $P\left(S_{t}^{T}=j \mid S_{t-1}^{P}=k, S_{t-1}^{T}=q\right)=P\left(S_{t}^{T}=j \mid S_{t-1}^{T}=q\right)$. Estimation of Models $2^{*}$ and $2^{* *}$ yields estimated likelihood values of 24.2 and 21.7 respectively. Comparing these to the likelihood value for Model 2, 26.35, shows that the likelihood deterioration from not allowing the state variable for the transitory component, $S_{t}^{T}$, to depend on $S_{t-1}^{P}$ is much greater than the likelihood deterioration from not allowing the state variable for the permanent component, $S_{t}^{P}$, to depend on $S_{t-1}^{T}$. The p-value for a likelihood ratio test of Model $2^{*}$ vs. Model 2 is 0.11 while the p-value for a likelihood ratio test of Model $2^{* * *}$ vs. Model 2 is .01 . Thus, it appears that the benefit of moving from Model 3 to Model 2 is 
concentrated in capturing the effects of $S_{t-1}^{P}$ on the evolution of $S_{t}^{T}$. However, this concentration is not complete, there is some, weaker, evidence that $S_{t-1}^{T}$ also effects the evolution of $S_{t}^{P}$.

\subsection{Estimation Results for Preferred Model}

We now move to a discussion of the estimation results for the preferred model, Model 2. We are interested in three questions: What sort of asymmetry is the model identifying? What can we learn about the relative importance of the permanent and transitory component? What does the model say about the pattern of switches in the permanent and transitory components between the boom state and the recession state?

Throughout the discussion, we have referred to the asymmetry that our model is meant to capture as business cycle asymmetry. Thus, we are first interested in whether the switches we identified in the dynamics of the permanent and transitory component match the timing of recessions for the U.S. economy. To check this, we look at whether the estimated filtered probabilities that either state variable is one coincides with the NBER recession dates. This probability is given by $P\left(S_{t}^{P}=1 \cup S_{t}^{T}=1 \mid t\right)=P\left(S_{t}^{P}=1, S_{t}^{T}=0 \mid t\right)+P\left(S_{t}^{P}=0, S_{t}^{T}=1 \mid t\right)+$ $P\left(S_{t}^{P}=1, S_{t}^{T}=1 \mid t\right)$. Figure 2 shows this probability along with the NBER recession dating.

During every recession with the exception of $1970 P\left(S_{t}^{P}=1 \cup S_{t}^{T}=1 \mid t\right)$ spikes up, but is essentially zero during expansions. (There is also a false positive during 1989, although the filtered probability is considerably lower than during any of the recessions.) Thus, our model is identifying recessions as periods where output and consumption undergo changes in dynamics.

Given this, what sort of business cycle asymmetry is the model identifying? The parameters of the permanent and transitory components unique to the recession state, $\left(\mu_{1}-\mu_{0}\right)$ and $\tau$, suggest differing dynamics in booms vs. recessions. Specifically, $\tau$ is estimated to be - 
1.46, implying that, when $S_{t}^{T}=1$, the transitory component is reduced by 1.46 percent. In the permanent component, $\mu_{1}$ is estimated to be less than $\mu_{0}$ by 0.6 , suggesting low growth and high growth phases for the trend component. In other words, the growth rate of the stochastic trend that would have occurred during an expansion is reduced during recessions. In sum, these parameter estimates suggest that recessions are characterized by a large reduction to the level of real GNP from what would have obtained had the recession not occurred. This reduction is asymmetric in the sense that it is better captured by discrete negative reductions present only during recessions rather than continuous, symmetric shocks present at all times.

Next, we consider various measures of the relative importance of the permanent and transitory components of real GNP. First, we investigate the relative importance of the discrete reductions to the permanent and transitory components during recessions. In the permanent component, average trend growth slows from roughly 1.0 percent per quarter when $S_{t}^{P}=0$ to 0.4 percent per quarter when $S_{t}^{P}=1$. As will be discussed further below, the transition probability estimates suggest that on average, $S_{t}^{P}=1$ for four quarters. Thus, the cumulative permanent loss in the level of output as a result of the switch to a recession state in the permanent component is about 2.4 percent. For each quarter that $S_{t}^{T}=1$, the transitory component is reduced by $\tau=-1.46$. On average, $S_{t}^{T}=1$ for two quarters, at which point the recession ends. Thus, in the last quarter of a recession, the cumulative effect of the discrete reduction to the transitory component is given by $\phi_{1} * \tau+\tau=-2.9$ percent, a bit larger than that for the permanent component.

What is the relative importance of the two continuous shocks, $v_{t}$ and $\varepsilon_{t}$, in explaining fluctuations in economic activity? First, note that the variance of both of these continuous shocks 
falls drastically after 1984 , with $\sigma_{v}^{k}$ and $\sigma_{\varepsilon}^{k}$ roughly half of $\sigma_{v}$ and $\sigma_{\varepsilon}$ respectively. This is consistent with Kim and Nelson (1999) and McConnell and Perez-Quiros (2000) who each document a large volatility reduction in the growth rates of real output growth beginning around 1984. The results presented here suggest that after 1984 the variance of continuous permanent shocks became somewhat more important relative to continuous transitory shocks. Before 1984, the variance of continuous transitory shocks were over 4 times as large as the variance of continuous permanent shocks. After 1984 this ratio was approximately 2.5.

If we aggregate the affects of the discrete and continuous shocks, what is the relative importance of the permanent and transitory components over the business cycle? One cannot directly compare the variances of $x_{t}$ and $z_{t}^{y}$ since $x_{t}$ is nonstationary. Instead we compare first differences. We find that $\operatorname{std} \operatorname{dev}\left(\Delta x_{t}\right)=0.46$ and $\operatorname{std} \operatorname{dev}\left(\Delta z_{t}^{y}\right)=0.93$. Thus the transitory component is quite important, at least in the short run. In sum, the evidence from these various measures suggest that both over the business cycle and within recessions, and with both the symmetric and asymmetric portion of dynamics, the transitory component accounts for a larger amount of variability in real GNP than the permanent component.

What are the relative sizes of discrete versus continuous shocks in a recessionary episode? For the permanent shocks, the standard deviation of continuous shocks is estimated to be $\sigma_{v}=0.40$ before the first quarter of 1984 and $\sigma_{v}^{k}=.23$ thereafter. The discrete reduction to the trend component, $\mu_{1}-\mu_{0}$ is thus one-and-a-half or two-and-a-half times the standard deviation of permanent continuous shocks depending on which part of the sample is considered. Considering the placement in the tail of the normal distribution, the discrete reductions to trend growth rate are larger than the absolute value of 87 percent of continuous shocks before the first quarter of 1984 and 98.5 percent of continuous shocks thereafter. For the transitory shocks, the 
standard deviation of continuous shocks is estimated to be $\sigma_{\varepsilon}=0.83$ before the first quarter of 1984 and $\sigma_{\varepsilon}^{k}=.36$ thereafter. Thus, $\tau$ equals one-and-three-quarters and four times the standard deviations of continuous transitory shocks depending on the time period. For transitory shocks, the discrete reductions to the transitory component are larger than the absolute value of 92 percent, or essentially all, continuous shocks.

We turn now to an examination of the temporal pattern of switches in the permanent and transitory component from boom to recession. The transition probabilities tell a very clear story about the pattern business cycles follow. The first column of Table 5 gives information about how recessions begin. When the economy was in a boom last period, that is $S_{t-1}^{P}=S_{t-1}^{T}=0$, the economy tends to stay in the boom: $S_{t}^{P}=S_{t}^{T}=0$ with probability 0.96 . The probability that a recession begins with both the transitory and permanent component switching at the same time, $p_{11 \mid 00}$, or just the transitory component switching, $p_{01 \mid 00}$, are both estimated to be zero to the third decimal place. Therefore, recessions begin with a switch in the dynamics of the permanent component, that is a reduction in the average growth rate of the stochastic trend shared by output and consumption.

The third column of transition probabilities in Table 5 indicate what then happens once this slowdown has begun, that is what happens when $S_{t-1}^{P}=1$ and $S_{t-1}^{T}=0$. The transition probabilities indicate that this state persists with $74 \%$ probability, that is $p_{10 \mid 10}=0.74$, while there is an $11 \%$ probability that the economy moves back into an expansion. Lastly, there is a $15 \%$ probability that the transitory component also switches to its recession state.

The fourth and second columns of Table 5 describe the chain of events once both the transitory and permanent components have entered the recession state. From the fourth column 
note that $p_{01 \mid 11}$ is estimated to equal 1 to the third decimal place. This indicates that the economy transits out of the full recession state after one quarter, entering a state in which only the transitory component is in its recession state. This indicates that the recessionary state in the permanent component ends before the recessionary state for the transitory component. Once in the state with only transitory type asymmetry, the economy switches back to a full expansion after 1 quarter, that is $p_{00 \mid 01}$ is estimated to equal 1 to three decimal places.

The above discussion can be summarized in the following chronology of recessions.

1) Once an expansion begins, we tend to stay in the expansion: $p_{00 \mid 00}=.96$.

2) Recessions begin with a slowdown in trend growth rate and not a discrete transitory shock: $p_{10 \mid 00}=.04, p_{01 \mid 00} \approx p_{11 \mid 00} \approx 0$.

3) Once a recession has begun, the economy stays in this state with $74 \%$ probability: $p_{10 \mid 10}=.74$. When the economy does shift states it moves to either a boom: $p_{00 \mid 10}=.11$ or to a recession with both types of asymmetric shocks present: $p_{11 \mid 10}=.15$.

4) If the economy moves to a state where both types of asymmetric shocks are present it then moves to the state where only the transitory component is in the recession state: $p_{01 \mid 11} \approx 1$. Thus, the permanent component switches back to the expansion state before the end of the recession.

5) Once in the state where only the transitory component is in recession, the recession ends after one quarter: $p_{00 \mid 01}=1$.

6) Because of the substantial serial correlation, $\phi_{1}+\phi_{2}=0.84$, the effect of the transitory parts of the recession are propagated for several quarters after the transitory component switches back to its expansion state.

The transition probabilities in Table 5 are in a sense averages across the historical record of recessions and do not give us any information regarding specific recessions. To analyze 
specific recessions more clearly, we can view the graphs of combinations of the filtered probabilities that one of the four states was occurring, that is $P\left(S_{t}^{P}=i, S_{t}^{T}=j \mid t\right) i, j=0,1$.

Figure 3 presents the probability that only the permanent type asymmetry is present, $P\left(S_{t}^{P}=1, S_{t}^{T}=0 \mid t\right)$, and the probability that the transitory type asymmetry is present, $P\left(S_{t}^{T}=1 \mid t\right)=P\left(S_{t}^{P}=0, S_{t}^{T}=1 \mid t\right)+P\left(S_{t}^{P}=1, S_{t}^{T}=1 \mid t\right)$ along with the NBER recession dating. This graph enables us to view graphically the tendency of the permanent component to lead the transitory component at the beginning of a recession. Figure 4 presents the probability that only the transitory component is present, $P\left(S_{t}^{P}=0, S_{t}^{T}=1 \mid t\right)$, and the probability that the permanent component is present, $P\left(S_{t}^{P}=1 \mid t\right)=P\left(S_{t}^{P}=1, S_{t}^{T}=0 \mid t\right)+P\left(S_{t}^{P}=1, S_{t}^{T}=1 \mid t\right)$ along with the NBER recession dating. This graph enables us to investigate the tendency of the permanent component to lead the transitory component of recessions.

In discussing Figures 3 and 4 two recessions should be separated from the rest. The first is the 1970 recession, which does not appear to be well characterized by business cycle asymmetry, in the sense that the probability of a switch in the dynamics of either the transitory or permanent component remains relatively low during the recession. The second is the 1990 recession, which appears to be characterized by only asymmetry in the trend component. This is consistent with Sichel (1994) and Kim and Murray (1999) who both present evidence that the 1990 recession does not have a peak-reverting component.

With regard to the remaining recessions, Figure 3 demonstrates that the probability of a switch in the permanent component, or a slowdown in trend growth rate, begins to rise one quarter or more before the probability of a switch in transitory component. The closest the two components switch together is the 1980 recession, however, even here $P\left(S_{t}^{P}=1, S_{t}^{T}=0 \mid t\right)$ rises 
to approximately 0.20 a full quarter before $P\left(S_{t}^{T}=1 \mid t\right)$ is appreciably different from zero.

Figure 4 demonstrates that once the recession has begun, the probability of recession state for the permanent component peaks before the probability of the recession state for the transitory component alone. Evidence of the recessionary state in the permanent component also generally peaks prior to the end of the official NBER dated recessions.

\subsection{Robustness Checks}

In the preceding, consumption played a key role in identifying the trend in real GNP. Our model assumes not only that output and consumption share a common stochastic trend, but also that consumption displays many characteristics implied by the permanent income hypothesis. In particular, the transitory component of consumption is not serially correlated and is completely uncorrelated with the transitory component of output.

Given these rather strong assumptions, a reasonable question is how the results regarding the dynamics of real GNP might change if these assumptions are relaxed. To assess this question we performed two experiments. In the first, we estimate an expanded version of the model given in (1-6), augmented to include more complex dynamics for consumption. Formally, the model is:

$$
\left[\begin{array}{l}
y_{t} \\
c_{t}
\end{array}\right]=\left[\begin{array}{l}
\alpha_{y} \\
0
\end{array}\right]+\left[\begin{array}{l}
1 \\
\gamma_{x}
\end{array}\right] x_{t}+\left[\begin{array}{l}
1 \\
\gamma_{z}
\end{array}\right] z_{t}+\left[\begin{array}{l}
e_{y t} \\
e_{c t}
\end{array}\right]
$$

where $x_{t}$, the common stochastic trend, is the same as in (2):

$$
x_{t}=\mu_{1}^{*} S_{t}^{P}+\mu_{0}^{*}\left(1-S_{t}^{P}\right)+x_{t-1}+v_{t}
$$

and

$$
\begin{aligned}
& \phi(L) z_{t}=\varepsilon_{t} \\
& \psi_{y}(L) e_{y t}=\tau_{y} S_{t}^{T}+\omega_{t}^{c} \\
& \psi_{c}(L) e_{c t}=\tau_{c} S_{t}^{T}+\omega_{t}^{y}
\end{aligned}
$$


where $\phi(L), \psi_{y}(L)$ and $\psi_{c}(L)$ have all roots outside the unit circle and $\varepsilon_{t} \sim N\left(0, \sigma_{\varepsilon}^{2^{*}}\right)$, $\omega_{t}^{c} \sim N\left(0, \sigma_{w^{c}}^{2}\right), \omega_{t}^{y} \sim N\left(0, \sigma_{w^{y}}^{2}\right)$ are uncorrected with each other and $v_{t}$. In this model, consumption is allowed to have much more complex dynamics in its transitory component. Specifically, consumption and output share a common transitory component, $z_{t}$, which allows for correlation between the transitory components of consumption and real GNP. Secondly, consumption is allowed to have an idiosyncratic transitory component that may be serially correlated. Finally, as for real GNP, consumption is allowed to undergo discrete reductions to its transitory component, given by $\tau_{c}$, in addition to its trend component.

We estimate this model, which we call model $2 \mathrm{R}$, with the transition probability restrictions of model 2 given in Section 2.2. The parameter estimates for model $2 \mathrm{R}$ are given in Table 6 while Table 7 contains the implied 4-state transition probabilities. Table 7 also contains the implied 4-state transition probabilities from Model 2, reproduced from Table 5, for comparison. The parameter estimates for Model $2 \mathrm{R}$ suggest that deviations of consumption from the common stochastic trend are more complex than a white noise process. Consistent with the permanent income hypothesis, the loading coefficient on the common transitory component shared with real GNP, $\gamma_{z}$, is small. This suggests that consumption does not share a large portion of this transitory component with real GNP. Also consistent with the permanent income hypothesis, the variance of symmetric shocks to the idiosyncratic transitory component of consumption are zero. However, inconsistent with the permanent income hypothesis, $\tau_{c} \neq 0$. Thus, similar to real GNP, it appears that consumption is well characterized by large, negative discrete shocks that drive consumption lower during recessions. The likelihood increase from allowing for the more complex consumption dynamics is 11 . Although models 2 and $2 \mathrm{R}$ are non- 
nested, making comparison of the likelihood increase problematic, this large increase in the likelihood value is suggestive that the added consumption dynamics are significant.

However, allowing for these additional dynamics in the consumption series has little effect on our conclusions regarding the dynamics of real GNP. First, the parameter estimates continue to indicate that both the permanent and transitory components of real GNP are occasionally hit by large discrete shocks. A plot of $P\left(S_{t}^{T}\right)+P\left(S_{t}^{P}\right)$ (not shown) indicates that the occurrence of these large negative shocks correspond to NBER recession dates. The parameter estimates do suggest some quantitative differences in the size of the discrete permanent shock. Specifically, $\mu_{1}-\mu_{0}$ is -.24 in Model $2 \mathrm{R}$ whereas it is -0.6 in Model 2. This is because Model 2R is attributing a portion of slower consumption growth during recessions to the discrete transitory shock, $\tau_{c}$. Given that the discrete transitory shock to the transitory component of real GNP, $\tau_{y}$, is roughly the same in Model $2 \mathrm{R}$ as in Model 2, the relative importance of permanent discrete shocks for real GNP is somewhat less in Model 2R than in Model 2. Second, the ordering of switches in the permanent and transitory components of real GNP between boom and recession are essentially unchanged from Model 2R. Table 7 shows that the estimated transition probabilities from Model 2R continue to have the strong implication that switches in the permanent component lead switches in the transitory component both when entering and leaving recessions.

As a second robustness check, we estimate a univariate version of model 2 on real GNP. As might be expected by the complexity of the model, the maximum likelihood estimates from univariate estimation were quite imprecise. However, when we impose the parameter estimates from the multivariate model pertaining to real GNP on the univariate model, the univariate model does not reject these parameters in favor of the maximum likelihood estimates, $(\mathrm{p}$-value $=$ 
0.25), suggesting the results given by allowing consumption to identify the trend are not rejected by a model basing the trend only on the univariate properties of real GNP.

\section{Conclusion}

In this paper we have investigated the relationship between permanent and transitory components of U.S. recessions in a model that explicitly incorporates business cycle asymmetry. In particular we specify a cointegrated model of real GNP and consumption which captures two types of business cycle asymmetry identified in U.S. output, regime switching in the average growth rate of the stochastic trend and "peak-reverting" regime switching in the transitory component. Using this model we investigate the relative importance of the permanent and transitory components of real GNP during recessionary episodes. We find that post-war recessions have been influenced by both the permanent and transitory component of real GNP, although the transitory component is somewhat larger. We also allow for the timing of switches from boom to recession in the permanent component to be correlated with switches from boom to recession in the transitory component. The parameter estimates suggest a specific pattern of recessions: Switches in the permanent component lead switches in the transitory component both when entering and leaving recessions. 


\section{References}

Acemoglu, D. and A. Scott (1997), 'Asymmetric business cycles: Theory and time-series evidence', Journal of Monetary Economics, 40, 501-533.

Bai, J., R.L. Lumsdaine and J.H. Stock (1998), 'Testing for and dating common breaks in multivariate time series', Review of Economic Studies, 65, 395-432.

Beaudry, P. and G. Koop (1993), 'Do recessions permanently change output?', Journal of Monetary Economics, 31, 149-163.

Burns, A.F. and W.A. Mitchell (1946), Measuring Business Cycles, NBER, New York.

Chauvet, M. (1998), 'An econometric characterization of business cycle dynamics with factor structure and regime switching', International Economic Review, 39, 969-996.

Chib, S. (1995), 'Marginal likelihood from the Gibbs output', Journal of the American Statistical Association, 90, 1313-1321.

Cochrane, J.H. (1994), 'Permanent and transitory components of GNP and stock prices', Quarterly Journal of Economics, 109, 241-263.

Cooper, R. (1994), 'Equilibrium selection in imperfectly competitive economies with multiple equilibria', Economic Journal, 104, 1106-1122.

Dickey, D.A. and W.A. Fuller (1979), 'Distribution of the estimators for autoregressive time series with a unit root', Journal of the American Statistical Association, 74, 427-31.

Diebold, F.X. and G.D. Rudebusch (1996), 'Measuring business cycles: A modern perspective', The Review of Economics and Statistics, 78, 67-77.

Evans, M.D.D. and K.K. Lewis, 1993, Trend in excess returns in currency and bond markets, European Economic Review, 37, 1005-1019.

Fama, E.F. (1992) 'Transitory variation in investment and output', Journal of Monetary Economics, 30, 467-480.

Friedman, M. (1964), Monetary Studies of the National Bureau, the National Bureau Enters its $45^{\text {th }}$ Year, $44^{\text {th }}$ Annual Report, 7-25, NBER, New York; Reprinted in Friedman, M. (1969), The Optimum Quantity of Money and Other Essays, Aldine, Chicago.

Friedman, M. (1993), 'The "plucking model” of business fluctuations revisited', Economic Inquiry, 31, 171-177.

Garcia, R. (1998), 'Asymptotic null distribution of the likelihood ratio test in Markov switching models', International Economic Review, 39, 763-788. 
Hamilton, J.D. (1989), 'A new approach to the economic analysis of nonstationary time series and the business cycle', Econometrica, 57, 357-384.

Hansen, B.E. (1992), 'The likelihood ratio test under nonstandard conditions: testing the Markov switching model of GNP', Journal of Applied Econometrics, 7, S61-S82.

Howitt, P. and McAfee, P. (1992), ‘Animal spirits', American Economic Review, 82, 493-507.

Kim, C.-J. (1993a), 'Unobserved-component time series models with Markov-switching heteroskedasticity: changes in regime and the link between inflation rates and inflation uncertainty', Journal of Business and Economic Statistics, 11, 341-349.

Kim, C.-J. (1993b), 'Sources of monetary growth uncertainty and economic activity: The time varying parameter model with heteroskedastic disturbances', Review of Economics and Statistics, 75, 483-492.

Kim, C.-J. (1994), 'Dynamic linear models with Markov-switching', Journal of Econometrics $60,1-22$.

Kim, C.-J. and C.J. Murray (1999), 'Permanent and transitory components of recessions', Discussion Paper, Department of Economics, University of Washington.

Kim, C.-J. and C.R. Nelson (1998), 'Business cycle turning points, a new coincident index, and tests for duration dependence based on a dynamic factor model with Markov Switching', The Review of Economics and Statistics, 80, 188-201.

Kim, C.-J. and C.R. Nelson (1999a), 'A Bayesian approach to testing for Markov-switching in univariate and dynamic factor models', International Economic Review, Forthcoming.

Kim, C.-J. and C.R. Nelson (1999b), 'Friedman's plucking model of business fluctuations: tests and estimates of permanent and transitory components', Journal of Money, Credit and Banking, 31, 317-34.

Kim, C.-J. and C.R. Nelson (1999c), 'Has the U.S. economy become more stable? A Bayesian Based Approach Based on a Markov Switching Model of the Business Cycle', Review of Economics and Statistics, Forthcoming.

Kim, C.-J. and J. Piger (1999), 'Common Stochastic Trends, Common Cycles, and Asymmetry in Economic Fluctuations', International Finance Discussion Paper, Federal Reserve Board of Governors.

Kim, M.-J. and J.-S. Yoo (1995), 'New index of coincident indicators: A multivariate Markov switching factor model approach', Journal of Monetary Economics, 36, 607-630.

King, R.G., C.I. Plosser, J.H. Stock and M.W. Watson (1991), 'Stochastic trends and economic fluctuations', American Economic Review, 81, 819-840. 
King, R.G., C.I. Plosser and S.T. Rebelo (1988), 'Production, growth and business cycles: II. new directions', Journal of Monetary Economics, 21, 309-341.

Koop, G. and S.M. Potter (1999), 'Bayes factors and nonlinearity: evidence from economic time series', Journal of Econometrics, 88, 251-281.

McConnell, M.M. and G.P. Quiros (2000), 'Output fluctuations in the United States: What has changed since the early 1980s?’, American Economic Review, 90, 1464-1476.

Neftci, S. N. (1984), 'Are economic time series asymmetric over the business cycle?', Journal of Political Economy, 92, 307-328.

Nelson, C.R., and Plosser, C.I. (1982), 'Trends and Random Walks in Macroeconomic Time Series: Some Evidence and Implications', Journal of Monetary Economics, 10, 139-162.

Perron, P. (1989), 'The great crash, the oil shock and the unit root hypothesis', Econometrica, 57, 1361-1401.

Sargent, T. (1989), 'Two models of measurements and the investment accelerator', Journal of Political Economy, 97, 251-287.

Sichel, D. E. (1994), 'Inventories and the three phases of the business cycle', Journal of Business and Economic Statistics, 12, 269-277.

Startz, R. (1998), 'Growth states and shocks', Journal of Economic Growth, 3, 203-215.

Stock, J.H. (1994), 'Unit Roots, Structural Breaks, and Trends', in R. Engle and D. McFadden (eds), Handbook of Econometrics, Volume IV, Elsevier, Amsterdam, 2740-2843.

Stock, J.H. and M.W. Watson, 1988, 'Variable trends in economic time series', Journal of Economic Perspectives, 2, 147-74.

Stock, J.H. and M.W. Watson, 1999, 'Business cycle fluctuations in U.S. macroeconomic time series', in J.B. Taylor and M. Woodford (eds), Handbook of Macroeconomics, Volume 1A, Elsevier, Amsterdam.

Wynne, M.A. and N.S. Balke (1992), 'Are deep recessions followed by strong recoveries?', Economics Letters, 39, 183-189.

Wynne, M.A. and N.S. Balke (1996), 'Are deep recessions followed by strong recoveries? Results for the G-7 countries', Applied Economics, 28, 889-897. 


\section{Table 1: Summary Statistics and Unit Root Tests for Log Real GNP, $y_{t}$, and Log Real Consumption of Non-Durables and Services $c_{t},(1952: 1-1998: 2)$}

\begin{tabular}{|c|c|c|}
\hline & \multicolumn{2}{|c|}{ Summary Statistics } \\
\hline & Mean & Std. Deviation \\
\hline $100 * \Delta y_{t}$ & 0.77 & 1.01 \\
\hline \multirow[t]{3}{*}{$100 * \Delta c_{t}$} & 0.81 & 0.49 \\
\hline & \multicolumn{2}{|c|}{ Augmented Dickey Fuller Tests ${ }^{8}$} \\
\hline & Dickey Fuller $t$-Statistic & 5\% Critical Value \\
\hline$y_{t}$ & -2.01 & -3.43 \\
\hline$c_{t}$ & -1.01 & -3.43 \\
\hline$y_{t}-c_{t}$ & -3.45 & -2.88 \\
\hline
\end{tabular}

\footnotetext{
${ }^{8}$ Augmented Dickey Fuller Tests were performed using BIC lag selection. One lag was chosen for real GNP, two for log real consumption of non-durables and services, and three for the $\log \mathrm{GNP} /$ consumption ratio. Tests for $\log$ real GNP and log real consumption of non-durables and services included a time trend and constant in the test regression. Tests for the log GNP / consumption ratio included a constant in the test regression.
} 


\section{Table 2: Maximum Likelihood Estimates of Model 1 \\ Quarterly data from 1952:1 - 1998:2 \\ (Standard Errors in Parentheses) ${ }^{9}$}

Parameter

\begin{tabular}{|c|c|c|c|c|}
\hline$P\left(S_{t}^{P}=0, S_{t}^{T}=0 \mid S_{t-1}^{P}=0, S_{t-1}^{T}=0\right)$ & $\begin{array}{l}0.96 \\
(0.02)\end{array}$ & & & \\
\hline$P\left(S_{t}^{P}=0, S_{t}^{T}=1 \mid S_{t-1}^{P}=0, S_{t-1}^{T}=0\right)$ & 0.00 & & & \\
\hline$P\left(S_{t}^{P}=1, S_{t}^{T}=0 \mid S_{t-1}^{P}=0, S_{t-1}^{T}=0\right)$ & $\begin{array}{l}0.04 \\
(0.02)\end{array}$ & & & \\
\hline$P\left(S_{t}^{P}=0, S_{t}^{T}=0 \mid S_{t-1}^{P}=0, S_{t-1}^{T}=1\right)$ & 1.00 & & & \\
\hline$P\left(S_{t}^{P}=0, S_{t}^{T}=1 \mid S_{t-1}^{P}=0, S_{t-1}^{T}=1\right)$ & 0.00 & & & \\
\hline$P\left(S_{t}^{P}=1, S_{t}^{T}=0 \mid S_{t-1}^{P}=0, S_{t-1}^{T}=1\right)$ & 0.00 & & & \\
\hline$P\left(S_{t}^{P}=0, S_{t}^{T}=0 \mid S_{t-1}^{P}=1, S_{t-1}^{T}=0\right)$ & $\begin{array}{l}0.11 \\
(0.09)\end{array}$ & & & \\
\hline$P\left(S_{t}^{P}=0, S_{t}^{T}=1 \mid S_{t-1}^{P}=1, S_{t-1}^{T}=0\right)$ & 0.00 & & & \\
\hline$P\left(S_{t}^{P}=1, S_{t}^{T}=0 \mid S_{t-1}^{P}=1, S_{t-1}^{T}=0\right)$ & $\begin{array}{l}0.74 \\
(0.12)\end{array}$ & & & \\
\hline$P\left(S_{t}^{P}=0, S_{t}^{T}=0 \mid S_{t-1}^{P}=1, S_{t-1}^{T}=1\right)$ & 0.00 & & & \\
\hline$P\left(S_{t}^{P}=0, S_{t}^{T}=1 \mid S_{t-1}^{P}=1, S_{t-1}^{T}=1\right)$ & 1.00 & & & \\
\hline$P\left(S_{t}^{P}=1, S_{t}^{T}=0 \mid S_{t-1}^{P}=1, S_{t-1}^{T}=1\right)$ & 0.00 & & & \\
\hline$\phi_{1}, \phi_{2}$ & $\begin{array}{l}0.97 \\
(0.08)\end{array}$ & $\begin{array}{l}-0.13 \\
(0.07)\end{array}$ & & \\
\hline$\sigma_{\varepsilon}, \sigma_{\varepsilon}^{k}, \sigma_{v}, \sigma_{v}^{k}$ & $\begin{array}{l}0.83 \\
(0.07)\end{array}$ & $\begin{array}{l}0.36 \\
(0.05)\end{array}$ & $\begin{array}{l}0.40 \\
(0.03)\end{array}$ & $\begin{array}{l}0.23 \\
(0.03)\end{array}$ \\
\hline$\tau$ & $\begin{array}{l}-1.46 \\
(0.39)\end{array}$ & & & \\
\hline$\mu_{0}, \mu_{1}, \mu^{k}$ & $\begin{array}{l}0.98 \\
(0.08)\end{array}$ & $\begin{array}{l}0.38 \\
(0.14)\end{array}$ & $\begin{array}{l}-0.26 \\
(0.07)\end{array}$ & \\
\hline$\gamma$ & $\begin{array}{l}1.07 \\
(0.06)\end{array}$ & & & \\
\hline$\sigma_{z^{c}}$ & $\begin{array}{l}0.12 \\
(0.03)\end{array}$ & & & \\
\hline Log Likelihood & 26.46 & & & \\
\hline
\end{tabular}

\footnotetext{
${ }^{9}$ Note that several of the estimated transition probabilities in Tables 1 and 3 are equal to the boundary values 0 and 1 to two digits. This violates conditions necessary for computing standard errors. Thus, while all parameters were estimated freely, these parameters were then constrained to their boundary value for calculation of the remaining standard errors.
} 
Table 3: Implied 4-State Transition Probabilities for Model 1

\begin{tabular}{|c|c|c|c|c|}
\hline & $\left(S_{t-1}^{P}=0, S_{t-1}^{T}=0\right)$ & $\left(S_{t-1}^{P}=0, S_{t-1}^{T}=1\right)$ & $\left(S_{t-1}^{P}=1, S_{t-1}^{T}=0\right)$ & $\left(S_{t-1}^{P}=1, S_{t-1}^{T}=1\right)$ \\
\hline$\left(S_{t}^{P}=0, S_{t}^{T}=0\right)$ & 0.96 & 1.00 & 0.11 & 0.00 \\
\hline$\left(S_{t}^{P}=0, S_{t}^{T}=1\right)$ & 0.00 & 0.00 & 0.00 & 1.00 \\
\hline$\left(S_{t}^{P}=1, S_{t}^{T}=0\right)$ & 0.04 & 0.00 & 0.74 & 0.00 \\
\hline$\left(S_{t}^{P}=1, S_{t}^{T}=1\right)$ & 0.00 & 0.00 & 0.15 & 0.00 \\
\hline
\end{tabular}


Table 4: Maximum Likelihood Estimates of Model 2

Quarterly data from 1952:1 - 1998:2

(Standard Errors in Parentheses)

Parameter

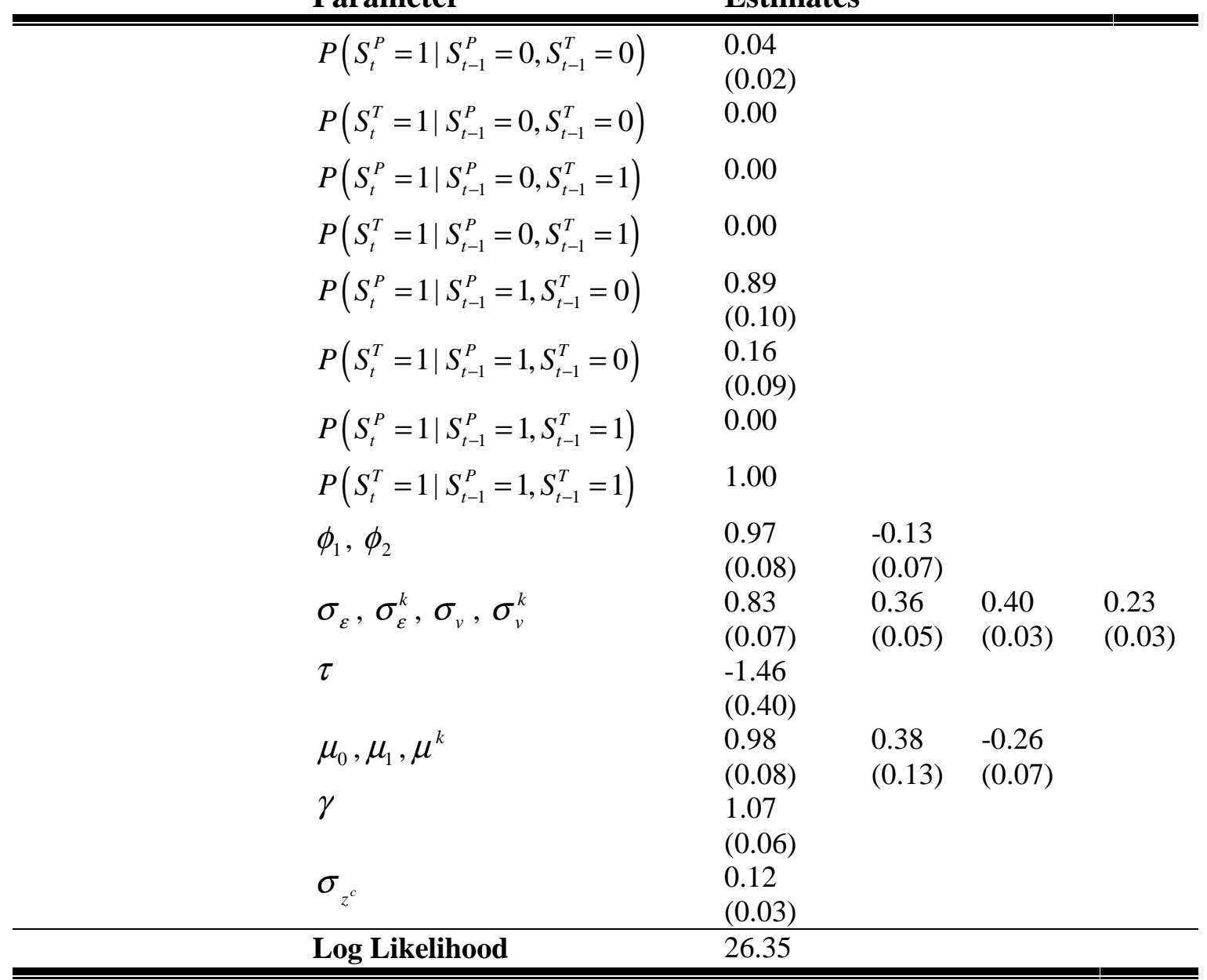


Table 5: Implied 4-State Transition Probabilities for Model 2

\begin{tabular}{l|c|c|c|c|}
\multicolumn{1}{c}{} & $\left(S_{t-1}^{P}=0, S_{t-1}^{T}=0\right)$ & $\left(S_{t-1}^{P}=0, S_{t-1}^{T}=1\right)$ & $\left(S_{t-1}^{P}=1, S_{t-1}^{T}=0\right)$ & $\left(S_{t-1}^{P}=1, S_{t-1}^{T}=1\right)$ \\
\cline { 2 - 5 }$\left(S_{t}^{P}=0, S_{t}^{T}=0\right)$ & 0.96 & 1.00 & 0.11 & 0.00 \\
$\left(S_{t}^{P}=0, S_{t}^{T}=1\right)$ & 0.00 & 0.00 & 0.00 & 1.00 \\
\cline { 2 - 5 }$\left(S_{t}^{P}=1, S_{t}^{T}=0\right)$ & 0.04 & 0.00 & 0.74 & 0.00 \\
$\left(S_{t}^{P}=1, S_{t}^{T}=1\right)$ & 0.00 & 0.00 & 0.15 & 0.00 \\
\cline { 2 - 5 } & & &
\end{tabular}


Table 6: Maximum Likelihood Estimates of Model 2R Quarterly data from 1952:1 - 1998:2

Parameter

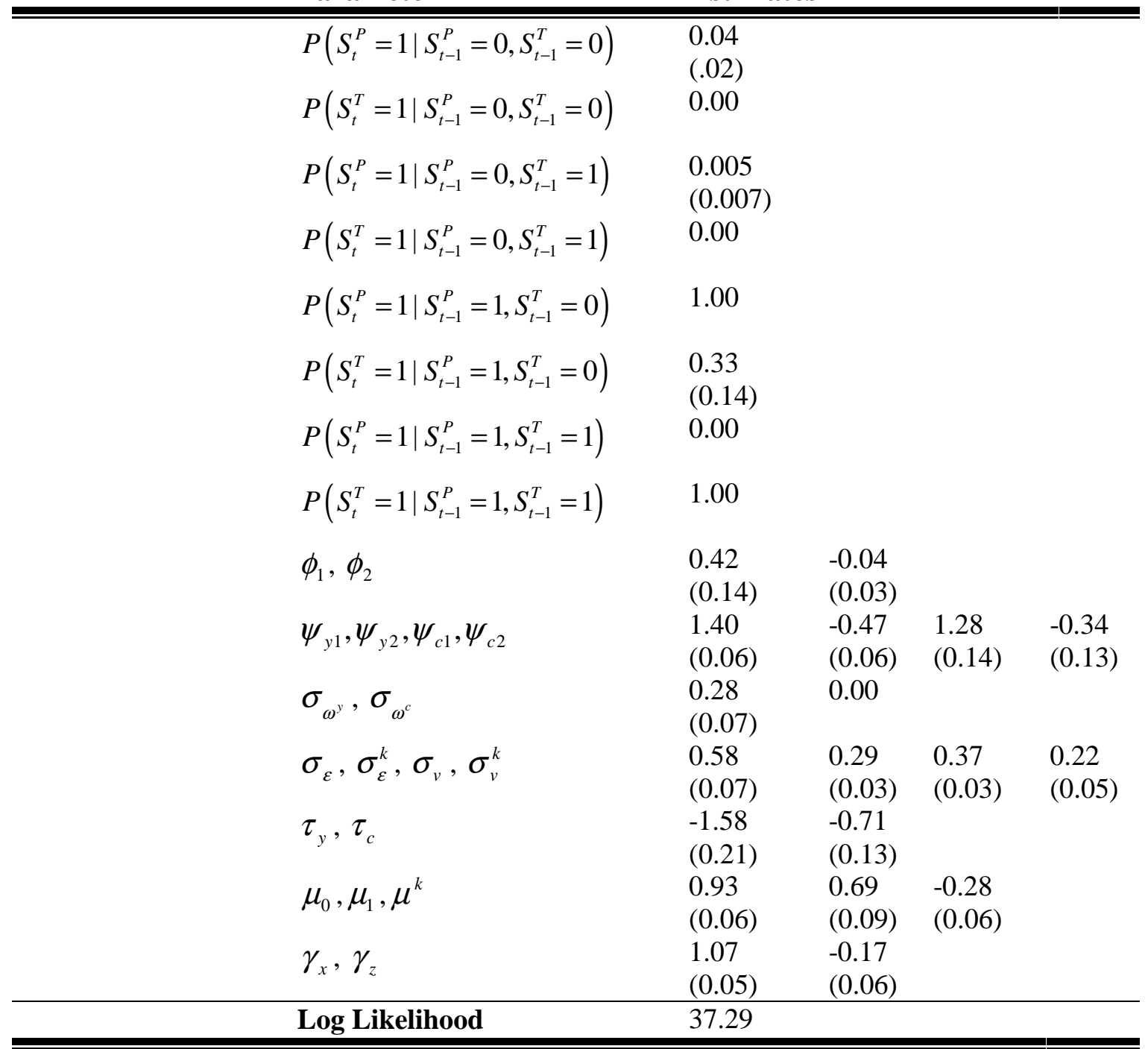


Table 7: Implied 4-State Transition Probabilities for Model 2 / Model 2R

\begin{tabular}{l|c|c|c|c|}
\multicolumn{1}{c}{} & $\left(S_{t-1}^{P}=0, S_{t-1}^{T}=0\right)$ & $\left(S_{t-1}^{P}=0, S_{t-1}^{T}=1\right)$ & $\left(S_{t-1}^{P}=1, S_{t-1}^{T}=0\right)$ & $\left(S_{t-1}^{P}=1, S_{t-1}^{T}=1\right)$ \\
\cline { 2 - 5 }$\left(S_{t}^{P}=0, S_{t}^{T}=0\right)$ & $0.96 / 0.96$ & $1.00 / 1.00$ & $0.11 / 0.00$ & $0.00 / 0.00$ \\
$\left(S_{t}^{P}=0, S_{t}^{T}=1\right)$ & $0.00 / 0.00$ & $0.00 / 0.00$ & $0.00 / 0.00$ & $1.00 / 1.00$ \\
\cline { 2 - 5 }$\left(S_{t}^{P}=1, S_{t}^{T}=0\right)$ & $0.04 / 0.04$ & $0.00 / 0.00$ & $0.74 / 0.66$ & $0.00 / 0.00$ \\
\cline { 2 - 5 }$\left(S_{t}^{P}=1, S_{t}^{T}=1\right)$ & $0.00 / 0.00$ & $0.00 / 0.00$ & $0.15 / 0.33$ & $0.00 / 0.00$ \\
\cline { 2 - 5 } & & &
\end{tabular}




\section{Figure 1: Typical Recession}

(Simulation of Model 2)

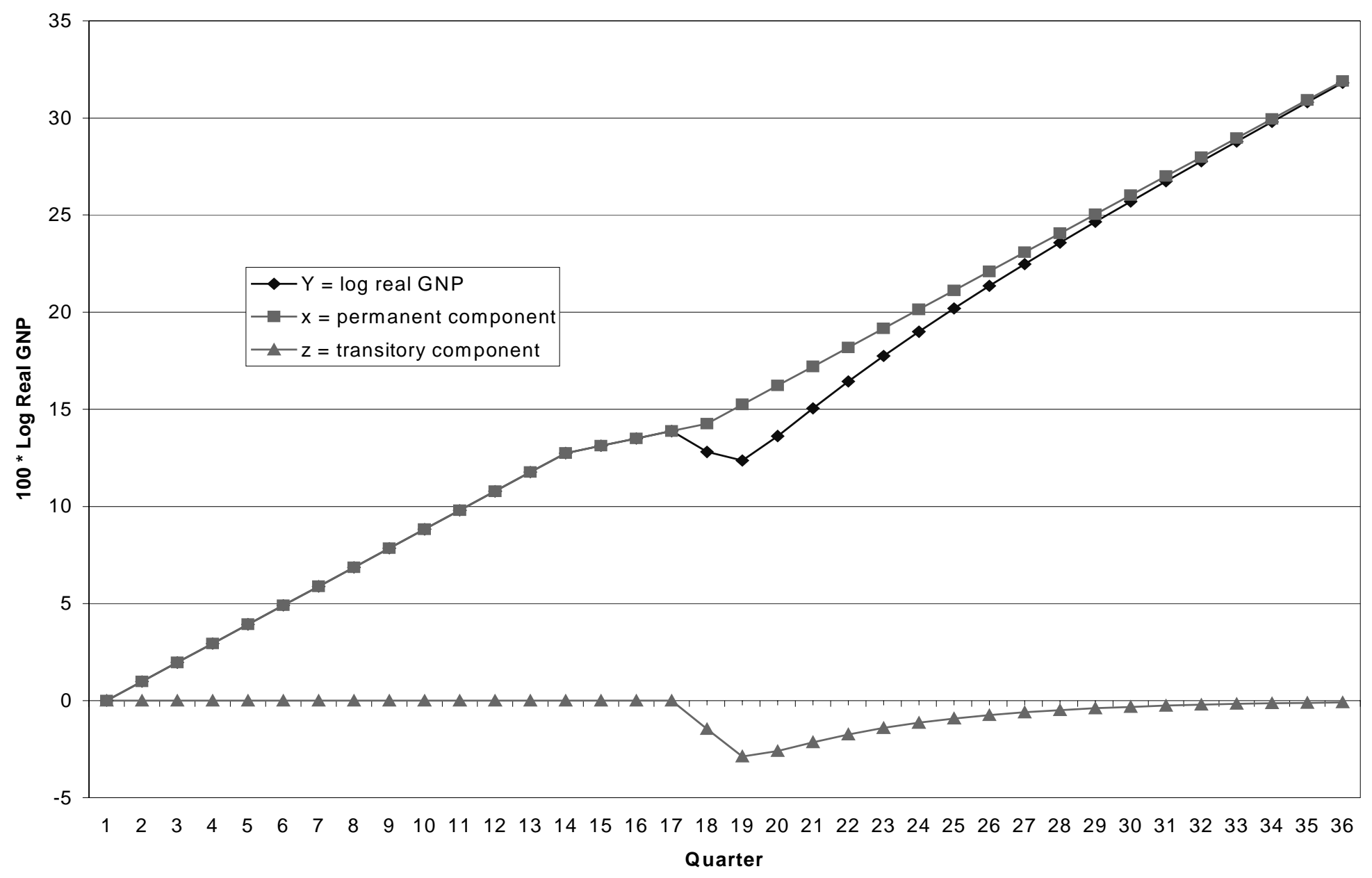


Figure 2: Filtered Probability that $S_{t}^{P}=1$ or $S_{t}^{T}=1, P\left(S_{t}^{P}=1 \cup S_{t}^{T}=1 \mid t\right)$ (Sample Period: 1952:1 - 1998:2, Shaded Areas Indicate NBER Recession Dates)

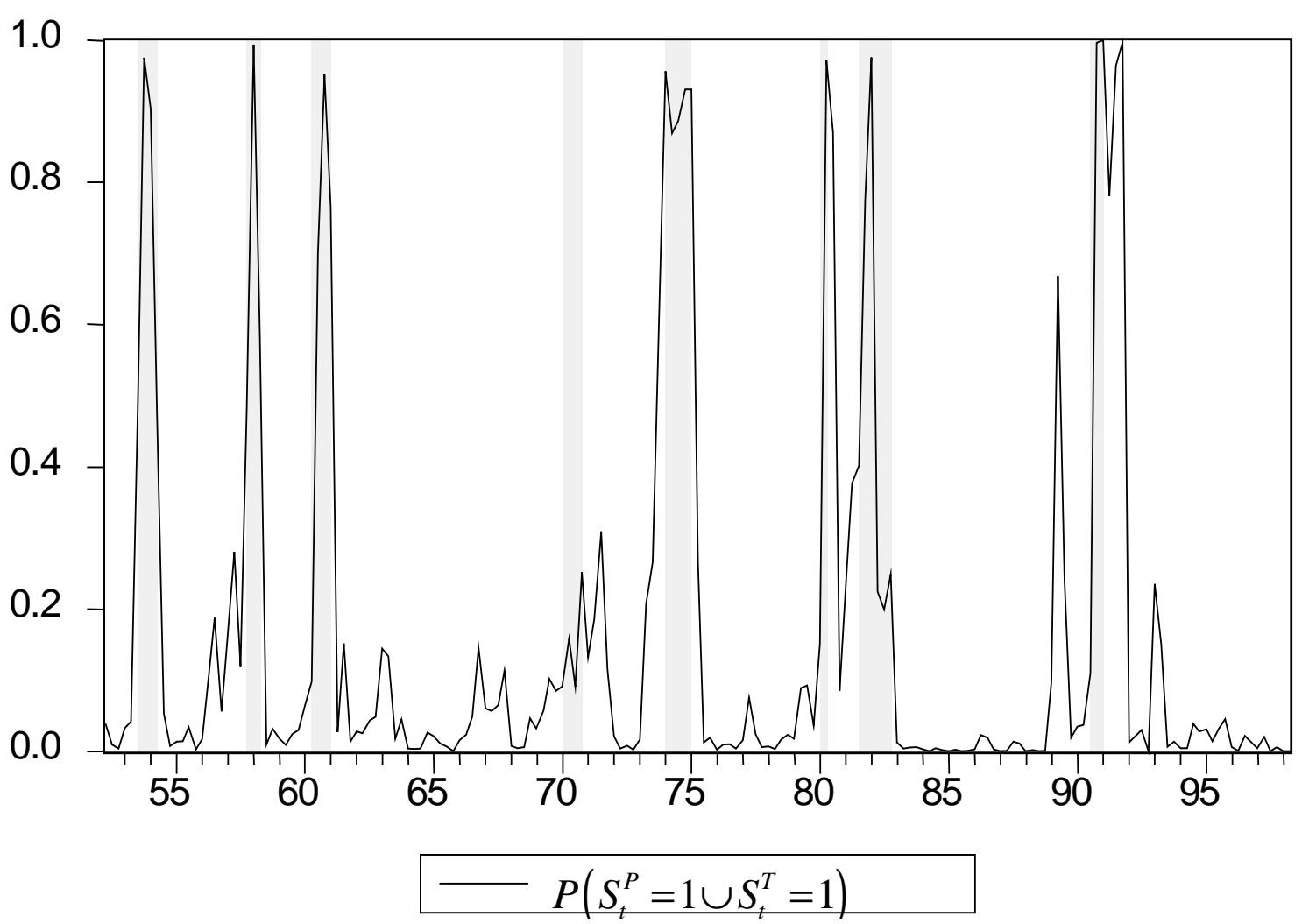


Figure 3: Filtered Probability of Trend Asymmetry Only $P\left(S_{t}^{P}=1, S_{t}^{T}=0 \mid t\right)$ and Filtered Probability of Transitory Asymmetry $P\left(S_{t}^{T}=1 \mid t\right)$

(Sample Period: 1952:1 - 1998:2, Shaded Areas Indicate NBER Recession Dates)

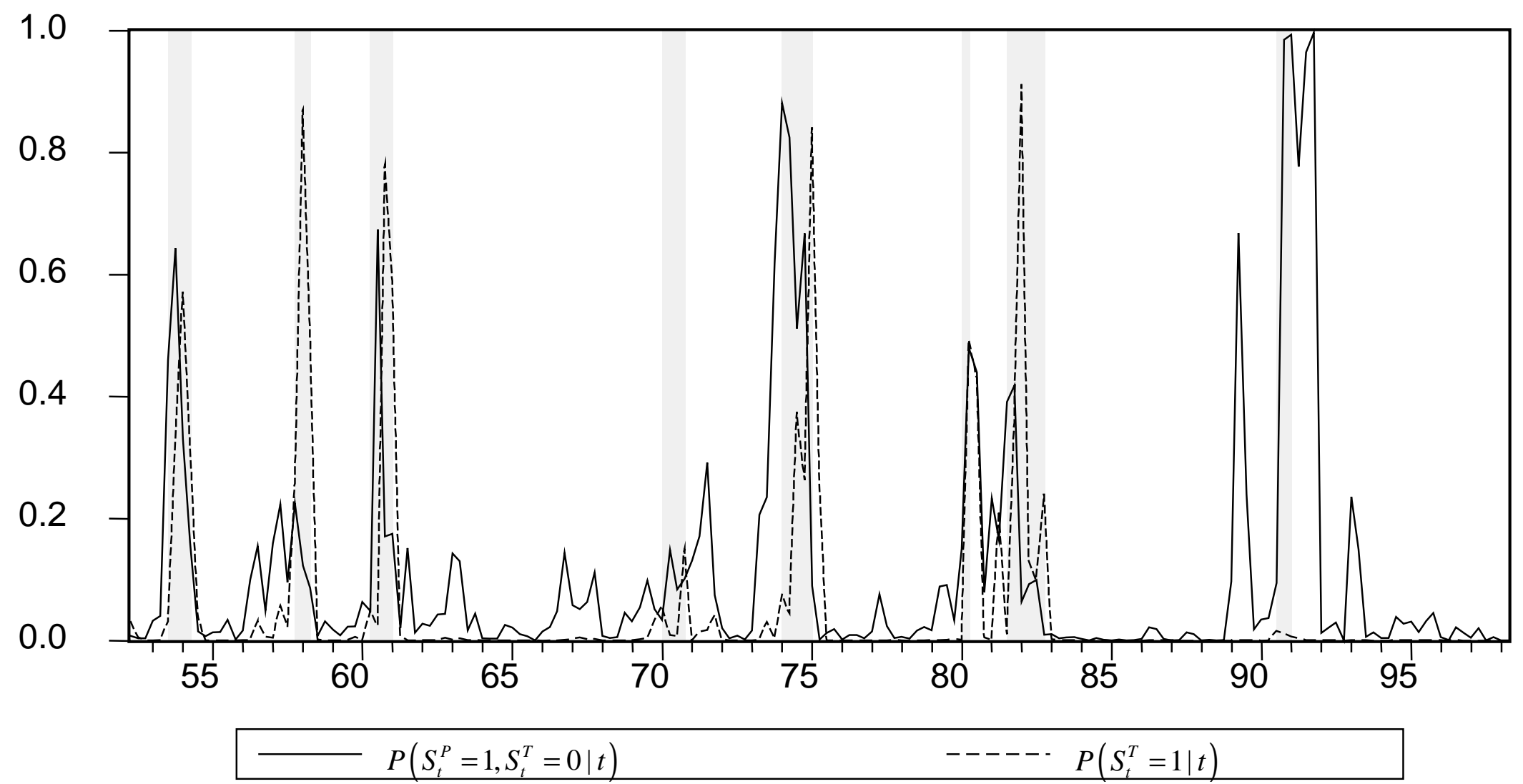


Figure 4: Filtered Probability of Transitory Asymmetry Only $P\left(S_{t}^{P}=0, S_{t}^{T}=1 \mid t\right)$ and

Filtered Probability of Trend Asymmetry $P\left(S_{t}^{P}=1 \mid t\right)$

(Sample Period: 1952:1 - 1998:2, Shaded Areas Indicate NBER Recession Dates)

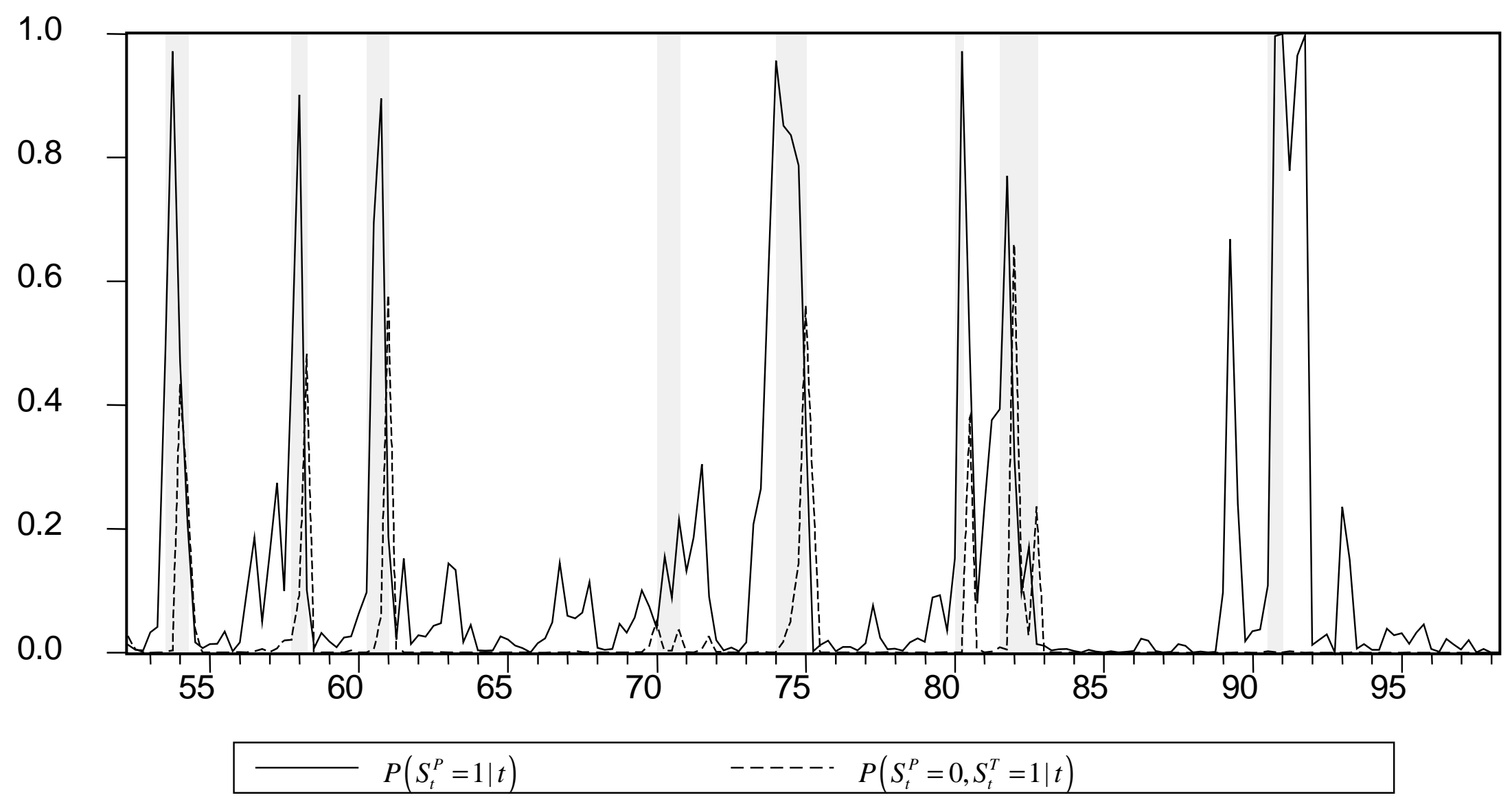




\section{Appendix A (not intended for publication): Specification of Transition Probabilities for Models 1-3.}

In this appendix we discuss the various specification of the transition probabilities that are estimated for models 1-3. Recall, there are four states in our business cycle model, corresponding to the four combinations of $S_{t}^{P}$ and $S_{t}^{T}$. There are then 16 transition probabilities of the first order Markov-switching process governing these four states, given by:

$P\left(S_{t}^{P}=i, S_{t}^{T}=j \mid S_{t-1}^{P}=k, S_{t-1}^{T}=q\right) i, j, k, q=0,1$

\section{Transition Probabilities for Model 1:}

In Model 1, the most general model, we estimate the transition probabilities exactly as in (1A). 12 such transition probabilities must be estimated while 4 can be recovered from adding up constraints.

\section{Transition Probabilities for Model 2:}

In Model 2, the transition probabilities are such that $S_{t}^{P}$ and $S_{t}^{T}$. are independent conditional on $S_{t-1}^{P}$ and $S_{t-1}^{T}$. Thus, we estimate transition probabilities of the form:

$P\left(S_{t}^{r}=w \mid S_{t-1}^{P}=k, S_{t-1}^{T}=q\right), r=P, T, w, k, q=0,1$

Here, there are 16 total transition probabilities, 8 which must be estimated and 8 which can be recovered from adding up constraints. These 16 transition probabilities can then be used to recover the 16 transition probabilities in (1A) as follows:

$P\left(S_{t}^{P}=i, S_{t}^{T}=j \mid S_{t-1}^{P}=k, S_{t-1}^{T}=q\right)=P\left(S_{t}^{P}=i \mid S_{t-1}^{P}=k, S_{t-1}^{T}=q\right) * P\left(S_{t}^{T}=j \mid S_{t-1}^{P}=k, S_{t-1}^{T}=q\right)$

\section{Transition Probabilities for Model 3:}

In Model 3, the transition probabilities are such that $S_{t}^{P}$ and $S_{t}^{T}$. are independent. Thus, we estimate transition probabilities of the form:

$P\left(S_{t}^{r}=w \mid S_{t-1}^{r}=l\right), r=P, T, w, l=0,1$

Here, there are 8 total transition probabilities, 4 which must be estimated and 4 which can be recovered from adding up constraints. These 8 transition probabilities can then be used to recover the 16 transition probabilities in (1A) as follows:

$P\left(S_{t}^{P}=i, S_{t}^{T}=j \mid S_{t-1}^{P}=k, S_{t-1}^{T}=q\right)=P\left(S_{t}^{P}=i \mid S_{t-1}^{P}=k\right) * P\left(S_{t}^{T}=j \mid S_{t-1}^{T}=q\right)$ 
Transition Probabilities for Model $2^{*}$

In Model $2^{*}$, the transition probabilities are such that the evolution of $S_{t}^{P}$ can be completely described based on $S_{t-1}^{P}$ only, while the evolution of $S_{t}^{T}$ can be described in terms of both $S_{t-1}^{P}$ and $S_{t-1}^{T}$. Thus, we estimate transition probabilities of the form:

$$
\begin{aligned}
& P\left(S_{t}^{P}=i \mid S_{t-1}^{P}=k\right), \quad i, k=0,1 \\
& P\left(S_{t}^{T}=j \mid S_{t-1}^{P}=k, S_{t-1}^{T}=q\right), j, k, q=0,1
\end{aligned}
$$

Here, there are 12 total transition probabilities, 6 which must be estimated and 6 which can be recovered from adding up constraints. These 12 transition probabilities can then be used to recover the 16 transition probabilities in (1A) as follows:

$P\left(S_{t}^{P}=i, S_{t}^{T}=j \mid S_{t-1}^{P}=k, S_{t-1}^{T}=q\right)=P\left(S_{t}^{P}=i \mid S_{t-1}^{P}=k\right) * P\left(S_{t}^{T}=j \mid S_{t-1}^{P}=k, S_{t-1}^{T}=q\right)$

Transition Probability for Model $2^{* *}$

In Model $2^{* *}$, the transition probabilities are such that the evolution of $S_{1 t}$ can be described in terms of both $S_{1 t-1}$ and $S_{2 t-1}$ while the evolution of $S_{2 t}$ can be completely described in terms of $S_{2 t-1}$. Thus, we estimate transition probabilities of the form:

$$
\begin{aligned}
& P\left(S_{t}^{T}=j \mid S_{t-1}^{T}=q\right), j, q=0,1 \\
& P\left(S_{t}^{P}=i \mid S_{t-1}^{P}=k, S_{t-1}^{T}=q\right), \quad i, k, q=0,1
\end{aligned}
$$

Here, there are 12 total transition probabilities, 6 which must be estimated and 6 which can be recovered from adding up constraints. These 12 transition probabilities can then be used to recover the 16 transition probabilities in (1A) as follows:

$$
P\left(S_{t}^{P}=i, S_{t}^{T}=j \mid S_{t-1}^{P}=k, S_{t-1}^{T}=q\right)=P\left(S_{t}^{P}=i \mid S_{t-1}^{P}=k, S_{t-1}^{T}=q\right) * P\left(S_{t}^{T}=j \mid S_{t-1}^{T}=q\right)
$$




\section{Appendix B: State Space Representation}

In this appendix we present the state-space representation used for estimation of the model given in equations 1-6. The state-space representation is written for the case where all transitory dynamics are $\operatorname{AR}(2)$.

Observation Equation:

$$
\left[\begin{array}{l}
\Delta y_{t} \\
\Delta c_{t}
\end{array}\right]=\left[\begin{array}{l}
\mu_{1}^{*} S_{t}^{P}+\mu_{0}^{*}\left(1-S_{t}^{P}\right) \\
\gamma^{*}\left(\mu_{1}^{*} S_{t}^{P}+\mu_{0}^{*}\left(1-S_{t}^{P}\right)\right)
\end{array}\right]+\left[\begin{array}{cccc}
1 & -1 & 0 & 0 \\
0 & 0 & 1 & -1
\end{array}\right]\left[\begin{array}{c}
z_{t}^{y} \\
z_{t-1}^{y} \\
z_{t}^{c} \\
z_{t-1}^{c}
\end{array}\right]+\left[\begin{array}{l}
v_{t} \\
\mathcal{v}_{t}
\end{array}\right]
$$

where, $\mu_{0}^{*}$ and $\mu_{1}^{*}$ are defined in equation 5 .

Transition Equation:

$$
\left[\begin{array}{l}
z_{t}^{y} \\
z_{t-1}^{y} \\
z_{t}^{c} \\
z_{t-1}^{c}
\end{array}\right]=\left[\begin{array}{l}
\tau S_{t}^{T} \\
0 \\
0 \\
0
\end{array}\right]+\left[\begin{array}{cccc}
\phi_{1} & \phi_{2} & 0 & 0 \\
1 & 0 & 0 & 0 \\
0 & 0 & 0 & 0 \\
0 & 0 & 1 & 0
\end{array}\right]\left[\begin{array}{c}
z_{t-1}^{y} \\
z_{t-2}^{y} \\
z_{t-1}^{c} \\
z_{t-2}^{c}
\end{array}\right]+\left[\begin{array}{l}
\varepsilon_{t} \\
0 \\
z_{t}^{c} \\
0
\end{array}\right]
$$

The covariance matrix of the disturbance vector in the observation equation is given by:

$E\left(\left[\begin{array}{l}v_{t} \\ \mathcal{w}_{t}\end{array}\right]\left[\begin{array}{ll}v_{t} & \mathcal{w}_{t}\end{array}\right]\right)=\left[\begin{array}{cc}1 & \gamma \\ \gamma & \gamma^{2}\end{array}\right] \sigma_{v}^{* 2}$

where, $\sigma_{v}^{* 2}$ is defined in equation 6 .

Finally, we have the covariance matrix of the disturbance vector in the transition equation:

$$
E\left(\left[\begin{array}{l}
\varepsilon_{t} \\
0 \\
z_{t}^{c} \\
0
\end{array}\right]\left[\begin{array}{llll}
\varepsilon_{t} & 0 & z_{t}^{c} & 0
\end{array}\right]\right)=\left[\begin{array}{llll}
\sigma_{\varepsilon}^{* 2} & 0 & 0 & 0 \\
0 & 0 & 0 & 0 \\
0 & 0 & \sigma_{z_{c}}^{2} & 0
\end{array}\right]
$$

where, $\sigma_{\varepsilon}^{* 2}$ is defined in equation 6 . 